\title{
Acúmulo de massa Seca e de Macronutrientes por Plantas de Glycine max e Solanum americanum ${ }^{1}$
}

\author{
Accumulation of Dry Mass and Macronutrients by Glycine max and Solanum americanum \\ Plants
}

\author{
BIANCO, S. ${ }^{2}$, CARVALHO, L.B. ${ }^{3}$, BIANCO, M.S. ${ }^{4}$ e PITELLI, R.A. ${ }^{5}$
}

\begin{abstract}
RESUMO - A soja é uma das principais culturas agrícolas do Brasil, sendo a sua produtividade muito influenciada pela competição exercida pelas plantas daninhas. Foram realizados dois experimentos em casa de vegetação, em Jaboticabal, SP, objetivando determinar o acúmulo de massa seca, assim como a distribuição e o acúmulo de macronutrientes em plantas de soja, no período de outubro de 2000 a fevereiro de 2001, e de Solanum americanum, no período de janeiro a maio de 1995. As plantas cresceram em vasos com capacidade de 7 litros, preenchidos com areia de rio lavada e peneirada; elas foram irrigadas diariamente com solução nutritiva. Os tratamentos foram representados pelas épocas de amostragem, realizada a intervalos de 14 dias, iniciando-se 21 dias após a emergência (DAE), até 161 DAE para S. americanum e 119 DAE para soja cv. BR-16 (precoce). O ponto de máximo acúmulo teórico de massa seca deu-se aos 104 DAE para a soja (35,0 g por planta) e 143 DAE para S. americanum $(179,62$ g por planta). Da emergência até 49 e $63 \mathrm{DAE}$, as folhas apresentaram maior participação no acúmulo de massa seca para soja e S. americanum, respectivamente. Após esses períodos, verificou-se, em ambas as espécies, inversão na representatividade das folhas por caules para a espécie daninha e por caules e, posteriormente, por estruturas reprodutivas, para a cultura. A taxa de absorção diária dos macronutrientes atingiu maiores valores entre 69 e $87 \mathrm{DAE}$ para a soja e entre 105 e $119 \mathrm{DAE}$ para a planta daninha. Considerando a média dos valores de pontos de inflexão observados para a cultura da soja, tem-se que aos $75 \mathrm{DAE}$ uma planta de soja acumula teoricamente 23,9 g de massa seca, 564,4 mg de N, 7,1 mg de P, 490,8 $\mathrm{mg}$ de K, 487,0 $\mathrm{mg}$ de Ca, 156,6 mg de $\mathrm{Mg}$ e 36,0 mg de S. Para o mesmo período, uma planta de $S$. americanum acumula teoricamente 33,75 g de massa seca, 875,96 mg de N, 88,46 mg de P, 983,54 mg de K, 647,60 mg de Ca, 100,93 mg de Mg e $42,15 \mathrm{mg}$ de $\mathrm{S}$.
\end{abstract}

Palavras-chave: análise de crescimento, maria-pretinha, nutrição mineral, soja.

\begin{abstract}
Soybean is one of the main crops in Brazil, but its productivity is very affected by weed competition. Two experiments were carried out in Jaboticabal, SP, Brazil, under greenhouse conditions to determine the accumulation and distribution of dry mass and macronutrients in soybean cv. BR-16, from October 2000 to February 2001, and Solanum americanum plants, from January to May 1995. Plants were grown in seven liter pots filled with river sand substrate and were daily irrigated with nutrient solution. The treatments were constituted by the times of samplings carried out at 14 day intervals, starting 21 days after emergence (DAE). Soybean evaluation was extended to $161 \mathrm{DAE}$, while S. americanum was extended to $119 \mathrm{DAE}$. The point of maximum theoretical accumulation of dry mass in soybean occurred at $104 \mathrm{DAE}$ (35.00 g per plant) while for S. americanum, it occurred at $143 \mathrm{DAE}$ (179.62 g per plant). From emergence until 49 and $63 \mathrm{DAE}$, leaves showed higher participation in dry mass accumulation of soybean and $\mathbf{S}$. americanum, respectively. After these periods, an inversion could be observed, with leaves being surpassed by stems for the weeds, and by stems and later, by reproductive structures, for the crop. Macronutrient
\end{abstract}

Recebido para publicação em 13.4.2011 e aprovado em 13.9.2011.

Prof. Livre Docente, Dep. de Biologia Aplicada à Agropecuária, FCAV/UNESP, 14884-900 Jaboticabal-SP, <sbianco@fcav.unesp.br>;

${ }^{3}$ Prof. Adjunto, Dep. de Agronomia, CAV/UDESC, 88520-000 Lages-SC, <lbcarvalho@cav.udesc.br>; 4 Pós-Graduação em Agronomia (Produção Vegetal), Bolsista CNPq, FCAV/UNESP, Jaboticabal-SP, <matbianco2004@yahoo.com.br>; ${ }^{5}$ Prof. Voluntário, Dep. de Fitossanidade, FCAV/UNESP, Jaboticabal-SP, <rapitelli@ecosafe.agr.br>.

Planta Daninha, Viçosa-MG, v. 30, n. 1, p. 87-95, 2012 
uptake rate reached higher values between 69 to 87 DAE for soybean and between 105 to 119 DAE for S. americanum. Considering the mean inflexion point values observed in soybean crop, at $75 \mathrm{DAE}$, it can be evidenced that one soybean plant theoretically accumulated $23.90 \mathrm{~g}$ of dry mass, $564.40 \mathrm{mg}$ of $\mathrm{N}, 7.10 \mathrm{mg}$ of $P, 490.80 \mathrm{mg}$ of $\mathrm{K}, 487.00 \mathrm{mg}$ of Ca, $156.60 \mathrm{mg}$ of $\mathrm{Mg}$ and $36.00 \mathrm{mg}$ of $\mathrm{S}$, while one $\mathbf{S}$. americanum plant theoretically accumulated $33.75 \mathrm{~g}$ of dry mass, $875.96 \mathrm{mg}$ of $\mathrm{N}, 88.46 \mathrm{mg}$ of $\mathrm{P}, 983.54 \mathrm{mg}$ of $\mathrm{K}, 647.60 \mathrm{mg}$ of $\mathrm{Ca}, 100.93 \mathrm{mg}$ of $\mathrm{Mg}$, and $42.15 \mathrm{mg}$ of $\mathrm{S}$.

\section{INTRODUÇÃO}

A soja (Glycine max) constitui-se na mais importante oleaginosa cultivada no mundo. No âmbito mundial, o Brasil é o segundo maior produtor e um dos principais exportadores dos grãos (Nepomuceno et al., 2007). A importância da soja para a humanidade é relevante, pelo fato de ser uma excelente fonte proteica e poder ser cultivada em quase todas as regiões do mundo.

$\mathrm{Na}$ literatura nacional e internacional é relatado que as plantas daninhas são, na maioria das vezes, as maiores responsáveis por reduções de produtividade da cultura da soja, com danos que ultrapassam aqueles causados por insetos-praga e fitopatógenos. Em revisão de Nepomuceno et al. (2007), os prejuízos causados pelas plantas daninhas variam de 32 a 95\% devido à presença de plantas daninhas nas áreas de cultivo de soja. As perdas de produção devem-se às interferências decorrentes da presença dessas plantas na lavoura. Entre as formas de interferência direta, Pitelli (1985) destaca a competição pelo espaço e pelos recursos de crescimento, como água, luz e nutriente.

Solanum americanum, vulgarmente conhecida por maria-pretinha, é uma planta nativa do continente americano. É uma planta anual que se reproduz por sementes, que podem germinar logo após a maturação ou apresentar dormência inicial; a viabilidade geralmente vai de 2 a 3 anos. É uma planta invasora cosmopolita de regiões tropicais e temperadas (Blanco \& Fratini, 1978). Essa espécie é encontrada em todo o Brasil, sobretudo nas áreas cultivadas (Bianco et al., 2010). Pereira \& Velini (2003) relacionaram S. americanum entre as espécies daninhas anuais mais frequentes na cultura da soja, na região dos cerrados. Essa Solanaceae apresenta emergência tardia e rápido desenvolvimento, causando sérios prejuizos na cultura de soja.

Alguns estudos foram realizados visando conhecer as curvas de crescimento e de acúmulo de nutrientes por espécies como Ipomoea nil (Duarte et al., 2008) e Solanum americanum (Bianco et al., 2010), entre outras. Esses ensaios foram realizados em casa de vegetação, mas não tiveram comparações com uma espécie cultivada.

Neste trabalho, objetivou-se estudar o acúmulo e a distribuição de massa seca, além dos macronutrientes, pelas plantas de $S$. americanum e de soja, durante seus ciclos de desenvolvimento, cultivadas em condições similares, porém não simultâneas, possibilitando comparações.

\section{MATERIAL E MÉTODOS}

Foram realizados dois experimentos em casa de vegetação, em Jaboticabal, SP, Brasil, no período de meados de novembro de 1995 a meados de abril de 1996, para S. americanum, e de outubro de 2000 a fevereiro de 2001, para a soja cv. BR-16. No primeiro experimento, estudou-se o acúmulo de massa seca, a alocação e o acúmulo de macronutrientes por plantas de S. americanum e, no segundo, por plantas de soja, utilizando-se como substrato areia de rio lavada e, como fonte de nutrientes, solução nutritiva completa de Hoagland \& Arnon (1950).

O substrato foi peneirado em tamis de $5 \mathrm{~mm}$ e acondicionado em vasos de plástico com capacidade para 7 litros, perfurados e conectados, por meio de mangueiras plásticas de $1,0 \mathrm{~cm}$ de diâmetro e $75 \mathrm{~cm}$ de comprimento, a frascos de vidro escuro com capacidade de 1 litro. A finalidade era coletar a solução percolada das irrigações e o posterior retorno destas aos vasos. Foram semeadas 50 sementes por vaso de S. americanum e 
20 sementes por vaso de soja. Em ambos os experimentos, quando as mudas atingiram dois pares de folhas verdadeiras totalmente expandidas, foi efetuado desbaste, deixandose quatro plantas por vaso.

Os vasos foram irrigados com a solução nutritiva completa, recebendo $25 \%$ da concentração original até a primeira amostragem e, depois, $50 \%$ até o final da fase experimental. Os vasos receberam volume de solução suficiente para iniciar a percolação para os vidros coletores. O número de irrigações diárias deu-se em função do crescimento das plantas e da demanda de água pelo sistema.

Os vasos foram distribuídos aleatoriamente na casa de vegetação e suas posições alteradas semanalmente, também aleatoriamente, permitindo assim a casualização das parcelas. O delineamento experimental foi inteiramente casualizado, com quatro repetições. Foram utilizadas nove e oito épocas de amostragem para $S$. americanum e para soja, respectivamente, de acordo com o ciclo de desenvolvimento das plantas.

Os tratamentos foram representados pelas épocas de amostragem, realizadas a intervalos de 14 dias, iniciando-se 21 dias após a emergência (DAE), até $161 \mathrm{DAE}$ para $S$. americanum e 119 DAE para soja.

Nas avaliações, as plantas foram separadas em raiz, caule, folhas e estruturas reprodutivas. A seguir, esses materiais foram lavados na seguinte sequência: rápida imersão em solução diluída de detergente neutro, lavagem e imersão em água destilada e, finalmente, imersão em água deionizada.

Após a lavagem, as diferentes partes das plantas foram acondicionadas em sacos de papel devidamente etiquetados e perfurados, para posterior secagem em estufa de circulação forçada de ar, a $60-70{ }^{\circ} \mathrm{C}$, por 96 horas. A determinação da massa seca foi efetuada em balança eletrônica com precisão de 0,001 g. Depois de seco e pesado, o material foi moído em micromoinho tipo Willey, malha 20, e armazenado em frascos de vidro hermeticamente fechados, sendo posteriormente analisado quanto ao teor de macronutrientes.

O material moído foi digerido via úmida, de acordo com o método proposto por Sarruge
\& Haag (1974). O nitrogênio total $\left(\mathrm{N}_{\text {total }}\right)$ e o fósforo $(\mathrm{P})$ foram determinados pelos métodos semimicro Kjedahl e colorimétrico do ácido fosfovanadato-molibdico, respectivamente, conforme descrito por Sarruge \& Haag (1974). Para determinação do potássio (K), do cálcio (Ca) e do magnésio $(\mathrm{Mg})$, foi utilizado o método descrito por Jorgensen (1977), por meio de espectrofotometria de absorção atômica. O S foi determinado pelo método turbidimétrico, descrito por Vitti (1989).

Por observação dos valores encontrados no teor total de cada nutriente, ao longo do ciclo da planta, foi possivel determinar a amplitude de variação do teor total de cada nutriente; para isso, foram observados o maior e o menor valor dos teores totais. Os acúmulos de nutrientes para cada uma das partes da planta foram conseguidos multiplicando-se o teor do nutriente pela massa seca correspondente. O acúmulo total foi obtido pelo somatório dos acúmulos das diferentes partes da planta, enquanto o teor médio da planta foi obtido pela relação entre o acúmulo total da planta e a massa seca total correspondente.

Para cálculo do acúmulo total teórico dos macronutrientes, utilizou-se a integral sob a equação exponencial ajustada, $Y=\exp$ $\left(\mathrm{a}+\mathrm{bx}+\mathrm{cx}^{2}\right)$, sendo $\mathrm{Y}=$ acúmulo do nutriente $\mathrm{e} \mathrm{x}=$ dias após a emergência, ajustando-se curvas de crescimento em função dos dias do ciclo de vida da planta, refletindo um esboço comportamental de cada espécie em relação à massa seca e ao nutriente estudado, com o auxílio do programa Statistica 6.0 (Statsoft, 2007). Na escolha da equação de regressão foram considerados a lógica do fenômeno biológico do crescimento e o valor do coeficiente de determinação. Os pontos de inflexão e de máximo da curva foram determinados pelas derivadas primeira e segunda da equação ajustada aos dados obtidos com o auxílio do programa Maple V (Chart et al., 1991).

\section{RESULTADOS E DISCUSSÃO}

Apesar da limitação de que os experimentos foram conduzidos em épocas distintas, para fins de discussão dos resultados, considera-se que a soja foi mais precoce na alocação de recursos para as estruturas reprodutivas (Figura 1). O acúmulo de massa seca pelas 


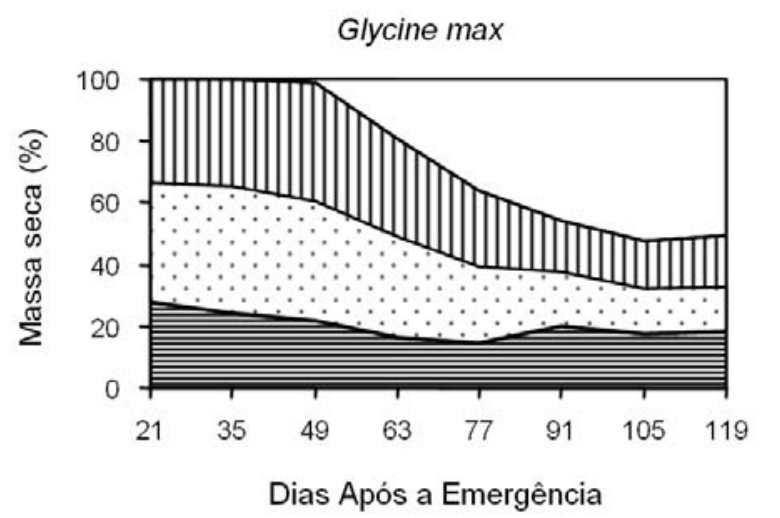

Raizes $\square$ CAULES DFOLHAS $\square$ P. REPR.

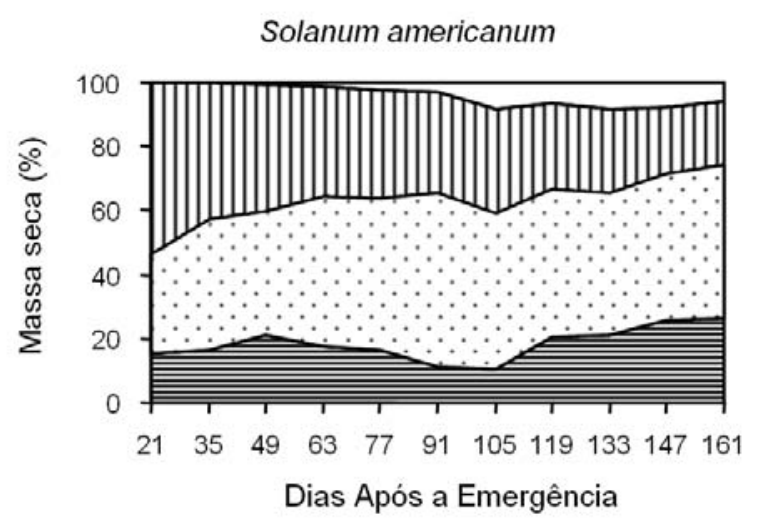

RAizes $\square$ CAULES DFOLHAS $\square$ P. REPR.

Figura 1 - Percentual da massa seca de soja e Solanum americanum distribuída em raízes, caules, folhas e estruturas reprodutivas ao longo de seus ciclos de desenvolvimento. Jaboticabal-SP, 2003.

estruturas reprodutivas das espécies em estudo foi crescente, a partir dos 49 DAE na soja e $63 \mathrm{DAE}$ em S. americanum, até o final da fase experimental, ou seja, $119 \mathrm{DAE}$ para a soja e 161 DAE para S. americanum. A soja acumulou cerca de $50 \%$, e $S$. americanum, aproximadamente $5,6 \%$, de massa seca nas estruturas reprodutivas, em relação à massa total. Esse acúmulo substancial de massa seca nas estruturas reprodutivas da soja é consequência do melhoramento genético, em que a produção de grãos é o principal objetivo do melhorista.

Duas considerações devem ser feitas quanto ao comportamento: (i) a planta daninha produziu e dispersou sementes ao longo do ciclo de desenvolvimento, sendo uma das principais características citadas por Baker (1974) para o sucesso de uma planta como infestante em campos agrícolas; e (ii) a soja, durante o processo de domesticação, perdeu a capacidade de dispersar suas sementes, produzindo acúmulo contínuo até o final do seu ciclo. Esse acúmulo ocorreu em detrimento da diminuição de recursos alocados para as demais estruturas das plantas, isto é, raízes, caules e folhas.

É importante destacar que, após o início do processo reprodutivo efetivo, $S$. americanum manteve equilíbrio na alocação de recursos para as diferentes partes da planta até o final do ciclo. Ou seja, as folhas - principal órgão na produção de fotossintatos - perderam rapidamente sua participação a partir da oitava semana de crescimento. Essa inversão, para espécies daninhas, também foi relatada por Carvalho et al. (2007) em B. plantaginea e Duarte et al. (2008) em I. nil, entre outros.

Nas Figuras 2 e 3 é possivel observar as diferenças nos teores de macronutrientes nas plantas de soja e $S$. americanum. As amplitudes dos valores das concentrações dos nutrientes avaliados durante o ciclo das plantas foram maiores em soja apenas para o magnésio. As amplitudes para nitrogênio, fósforo, potássio, cálcio e enxofre foram maiores para S. americanum. Ao observar as Figuras 2 e 3, pode-se evidenciar maior adaptação da espécie daninha em relação à espécie cultivada. Essa diferenciação é notada principalmente nas variações de nitrogênio, fósforo, potássio, cálcio e enxofre, evidenciando adaptação da espécie daninha a solos com diferentes niveis de fertilidade.

Quanto ao acúmulo de massa seca (Figura 4) e de macronutrientes (Figuras 5 a 10), para as duas espécies, o comportamento foi semelhante dentro de cada espécie e diferente entre as espécies, tendo pontos de máximo acúmulo teóricos variando entre 96 e 111 DAE para a cultura da soja e de 140 e 164 DAE para a espécie daninha. Os pontos de inflexão ficaram em torno de 69 a 87 DAE para a da soja e de 105 a 119 DAE para a planta daninha. Os valores obtidos para a planta 


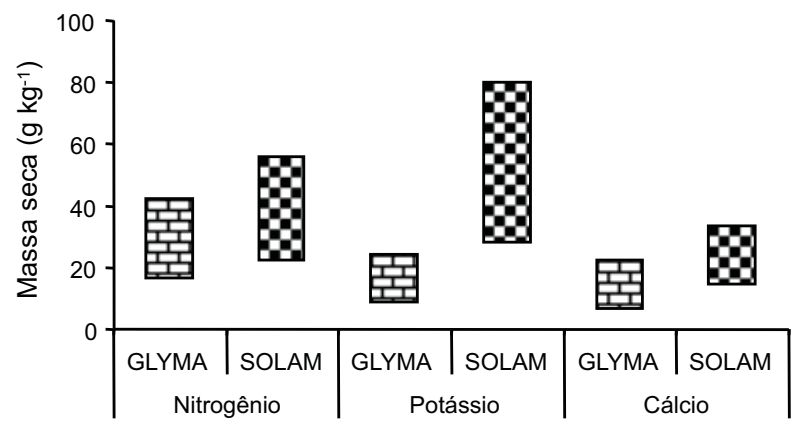

Figura 2 - Amplitude do teor total de nitrogênio, potássio e cálcio nas plantas de soja e Solanum americanum quando cultivadas em substrato de areia e irrigadas com solução nutritiva. Jaboticabal-SP, 2003.

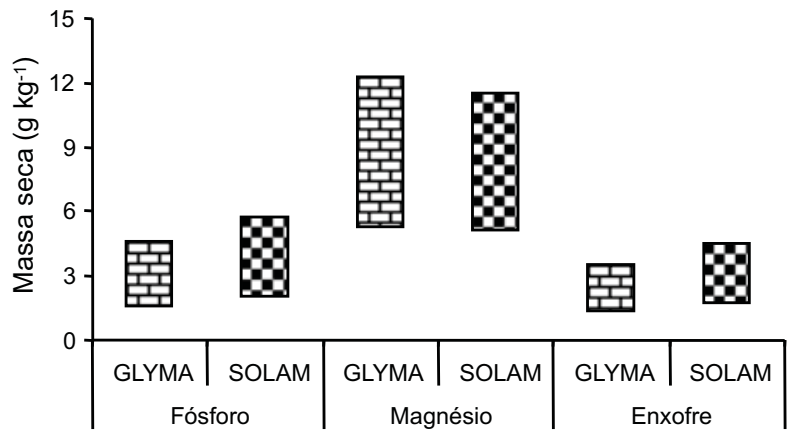

Figura 3 - Amplitude do teor total de fósforo, magnésio e enxofre nas plantas de soja e Solanum americanum quando cultivadas em substrato de areia e irrigadas com solução nutritiva. Jaboticabal-SP, 2003. daninha em questão foram maiores que os encontrados por Pedrinho Júnior et al. (2004) em $R$. brasiliensis. A discrepância entre os valores observados em cada espécie é notada para todos os macronutrientes analisados, porém é explicável observando-se os pontos de máximo acúmulo de massa seca e o ciclo das duas plantas estudadas.

O acúmulo máximo de massa seca total na cultura da soja ocorreu aos $104 \mathrm{DAE}$, com o valor teórico de $35 \mathrm{~g}$ de massa seca por planta, e aos 142 DAE para $S$. americanum, com o valor teórico de 179,62 g por planta de massa seca (Figura 4). Esse valor é inferior ao encontrado em outras plantas daninhas infestantes da cultura da soja, como B. plantaginea (Carvalho et al., 2007) e I. nil (Duarte et al., 2008), entre outros, e, quando considerado o período em que estas podem conviver com a cultura (0-148 DAE).

O valor do ponto de inflexão pode ser entendido como sendo o dia em que o acúmulo diário dos macronutrientes da planta chegou ao seu valor máximo, sendo a taxa de absorção diária crescente até esse momento: 70,69 , $87,77,78$ e 74 DAE para N, P, K Ca, Mg e S, respectivamente, nas plantas de soja, e 107, $117,105,105,116$ e $119 \mathrm{DAE}$ para N, P, K, Ca, $\mathrm{Mg}$ e $\mathrm{S}$, respectivamente, para plantas de S. americanum (Figuras 5 a 10). Huett \& Dettman (1988) e Fayad et al. (2002) utilizaram o mesmo parâmetro para determinar o
Glycine max

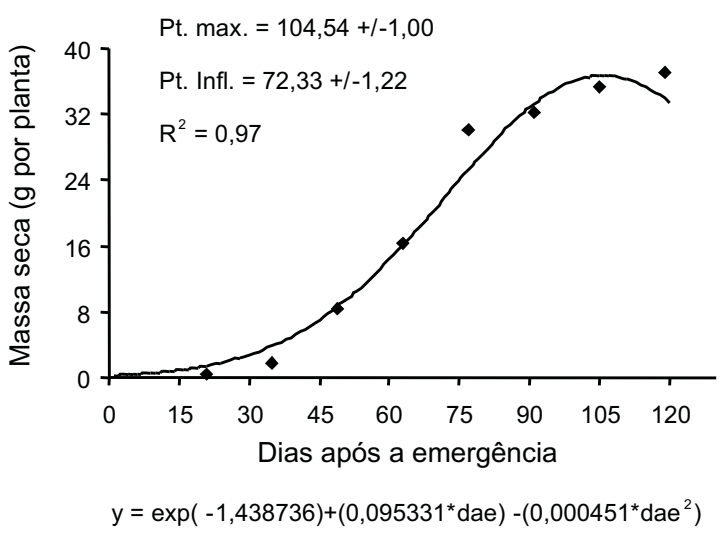

Solanum americanum

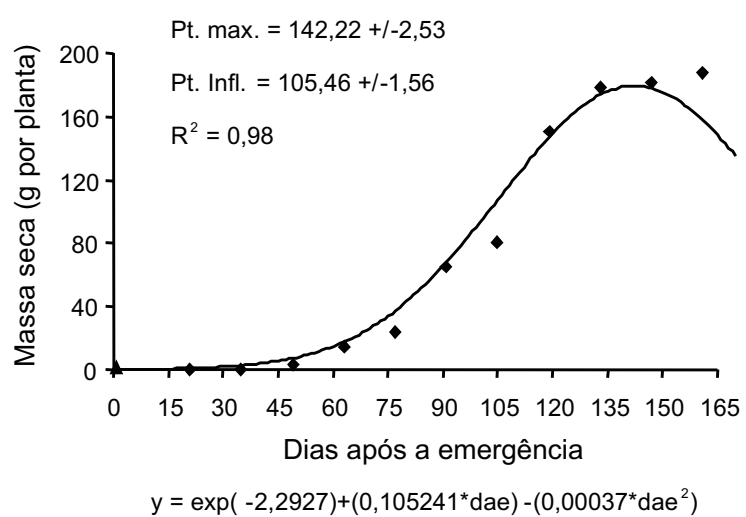

Figura 4 - Curvas de acúmulo de massa seca total (mg por planta) para soja e Solanum americanum, equações médias ajustadas com os respectivos coeficientes de determinação, seus pontos de máxima (Pt max) e de inflexão (Pt infl) e o coeficiente de determinação $\left(\mathrm{R}^{2}\right)$ dos pontos estudados, nas quatro repetições. Jaboticabal-SP, 2003. 
Glycine max

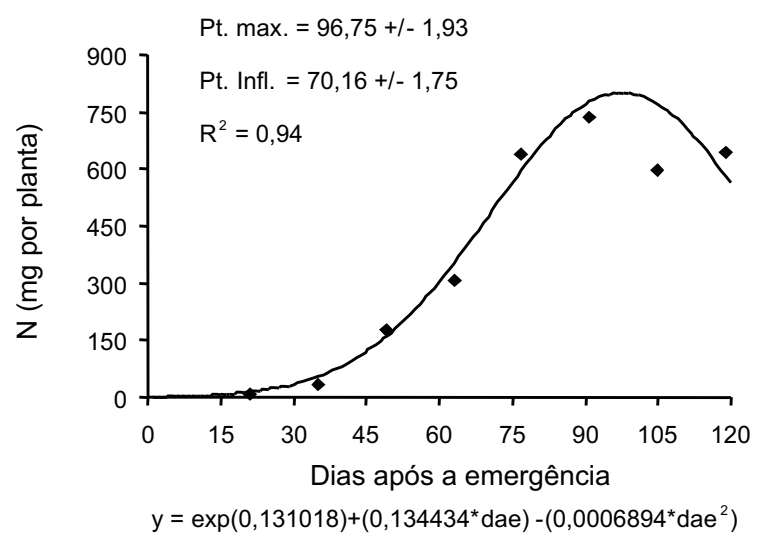

Solanum americanum

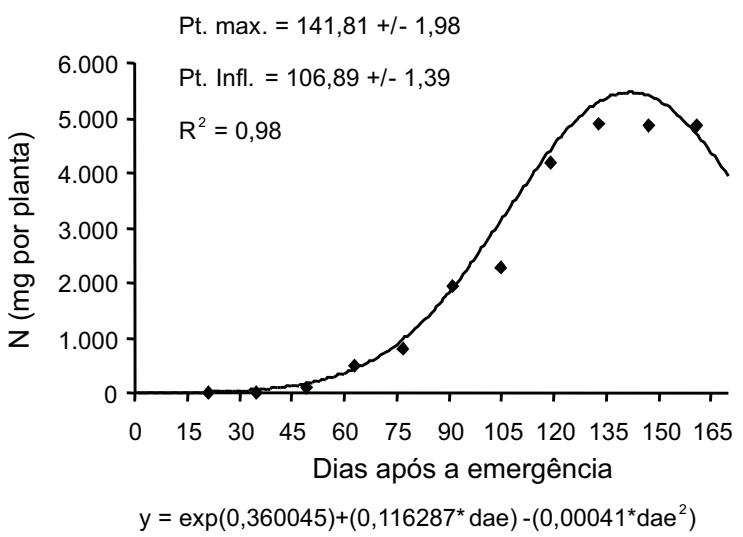

Figura 5 - Curvas de acúmulo total de nitrogênio (mg por planta) para soja e Solanum americanum, equações médias ajustadas com os respectivos coeficientes de determinação, seus pontos de máxima (Pt max) e de inflexão (Pt infl) e o coeficiente de determinação $\left(\mathrm{R}^{2}\right)$ dos pontos estudados, nas quatro repetições. Jaboticabal-SP, 2003.

Glycine max

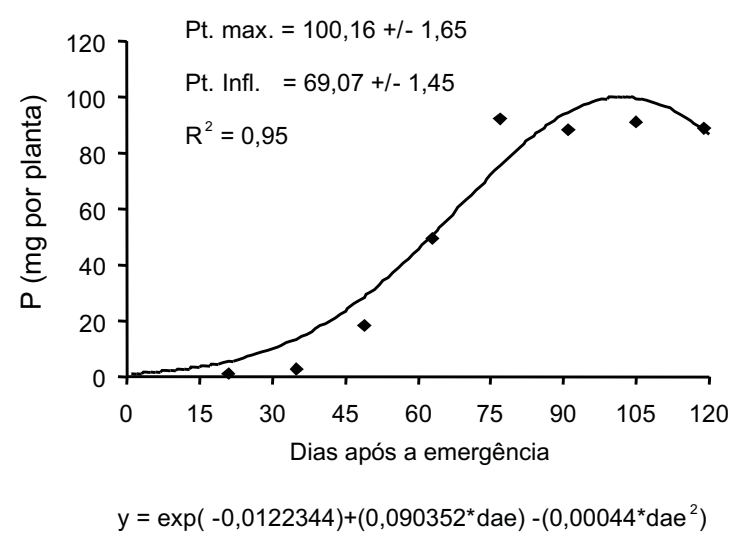

Solanum americanum

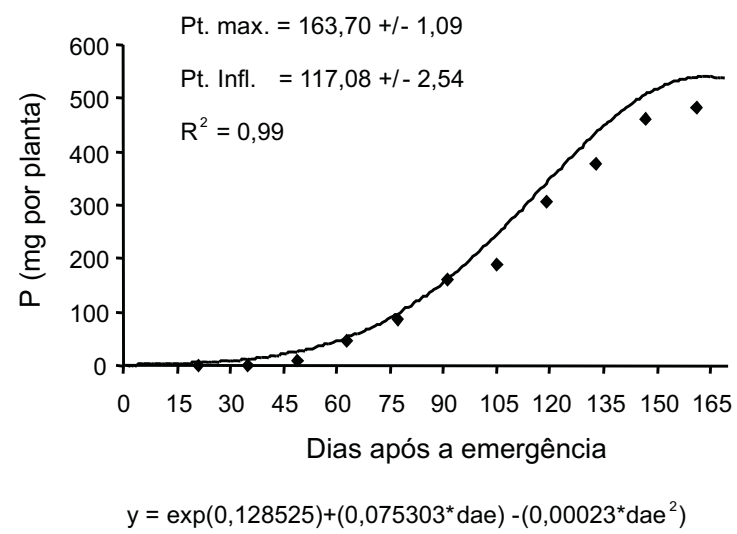

Figura 6 - Curvas de acúmulo total de fósforo (mg por planta) para soja e Solanum americanum, equações médias ajustadas com os respectivos coeficientes de determinação, seus pontos de máxima Pt max) e de inflexão (Pt infl) e o coeficiente de determinação $\left(\mathrm{R}^{2}\right)$ dos pontos estudados, nas quatro repetições. Jaboticabal-SP, 2003.

máximo acúmulo diário de macronutrientes em tomateiros, sendo relatado, pelos últimos autores, 46, 39, 51, 45, 15 e 44 dias após o transplante das mudas para N, P, K, Ca, Mg e $\mathrm{S}$, respectivamente.

É possivel que as diferenças na taxa de absorção de um nutriente ao longo do ciclo de vida da planta sejam reguladas por um controle no tipo ou na atividade do transportador. Como exemplo, o transporte ativo de $\mathrm{K}^{+}$ocorre quando ele está em concentrações externas muito pequenas, e o passivo (de baixa afinidade), quando há altas concentrações desse nutriente. O tipo de transporte e a disponibilidade dos nutrientes no meio influenciam diretamente a taxa de absorção do elemento, que por sua vez afetará o acúmulo deste, pois somente se podem observar altos valores de acúmulo de um dado nutriente quando, antecipadamente, há alta absorção deste.

De modo geral, o máximo acúmulo diário dos nutrientes coincidiu com o período inicial de frutificação de ambas as espécies, como também observado por Fayad et al. (2002) em tomateiros. Nesse período ocorre o estabelecimento de uma força mobilizadora de 
Glycine max

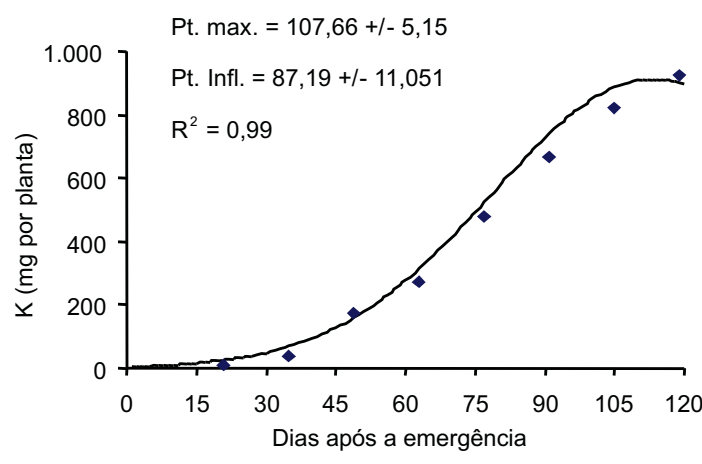

$y=\exp (1,40323)+\left(0,0955927^{*}\right.$ dae $)-\left(0,000422^{*}\right.$ dae $\left.^{2}\right)$
Solanum americanum

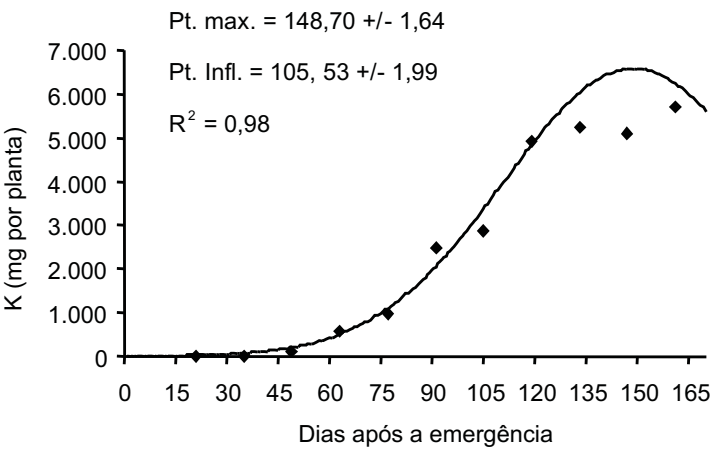

$y=\exp (1,05338)+\left(0,104087^{*}\right.$ dae $)-\left(0,00029^{*}\right.$ dae $\left.^{2}\right)$

Figura 7 - Curvas de acúmulo total de potássio (mg por planta) para soja e Solanum americanum, equações médias ajustadas com os respectivos coeficientes de determinação, seus pontos de máxima (Pt max) e de inflexão (Pt infl) e o coeficiente de determinação $\left(\mathrm{R}^{2}\right)$ dos pontos estudados, nas quatro repetições. Jaboticabal-SP, 2003.
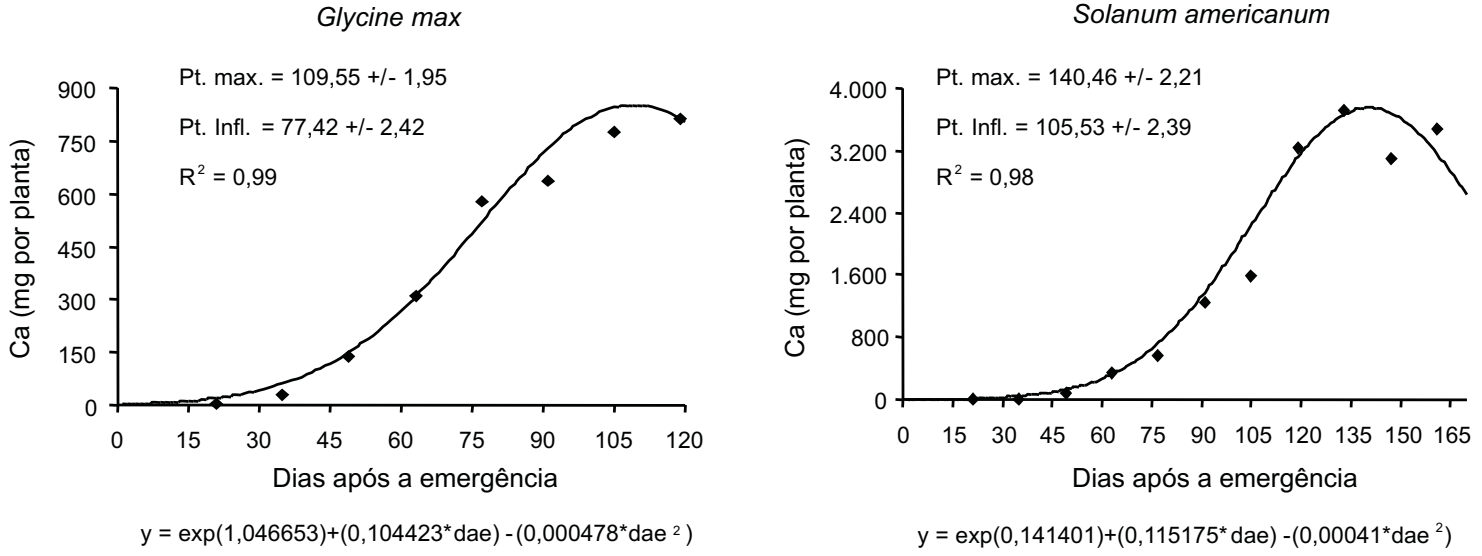

Figura 8 - Curvas de acúmulo total de cálcio (mg por planta) para soja e Solanum americanum, equações médias ajustadas com os respectivos coeficientes de determinação, seus pontos de máxima (Pt max) e de inflexão (Pt infl) e o coeficiente de determinação $\left(\mathrm{R}^{2}\right)$ dos pontos estudados, nas quatro repetições. Jaboticabal-SP, 2003.

\section{Glycine max}

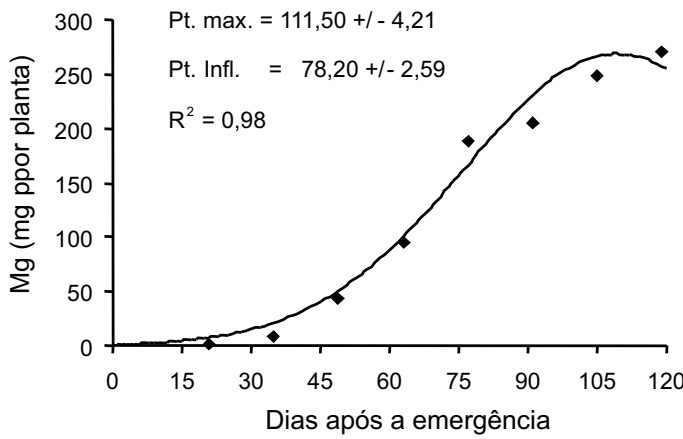

$y=\exp (0,101404)+\left(0,1005576^{*}\right.$ dae $)-\left(0,00046^{*} d^{2} e^{2}\right)$
Solanum americanum

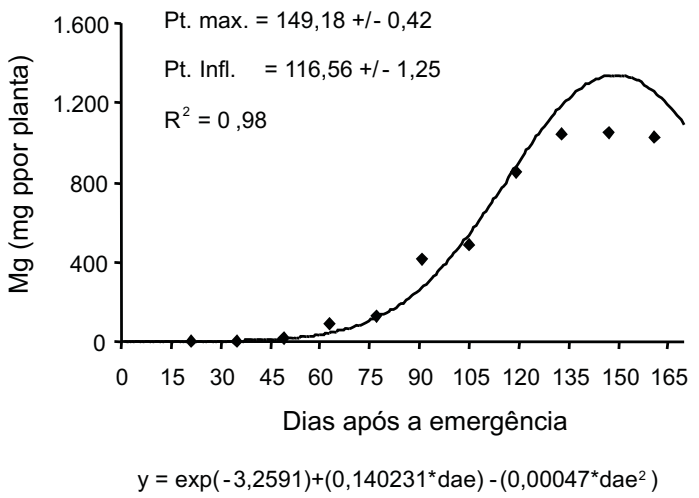

Figura 9 - Curvas de acúmulo total de magnésio (mg por planta) para soja e Solanum americanum, equações médias ajustadas com os respectivos coeficientes de determinação, seus pontos de máxima (Pt max) e de inflexão (Pt infl) e o coeficiente de determinação $\left(\mathrm{R}^{2}\right)$ dos pontos estudados, nas quatro repetições. Jaboticabal-SP, 2003. 
Glycine max

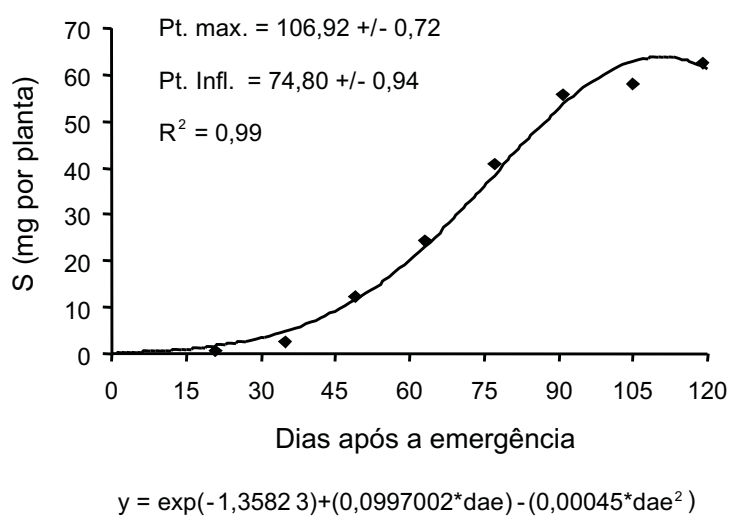

Solanum americanum

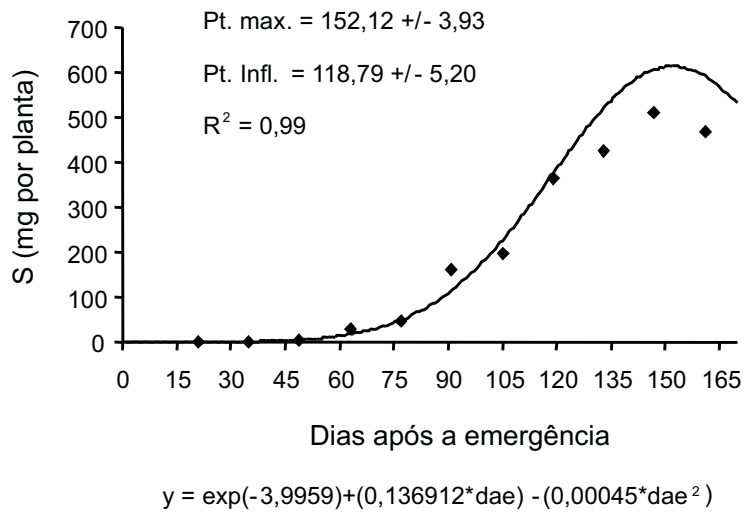

Figura 10 - Curvas de acúmulo total de enxofre (mg por planta) para soja e Solanum americanum, equações médias ajustadas com os respectivos coeficientes de determinação, seus pontos de máxima (Pt max) e de inflexão (Pt infl) e o coeficiente de determinação $\left(\mathrm{R}^{2}\right)$ dos pontos estudados, nas quatro repetições. Jaboticabal-SP, 2003.

nutrientes e assimilados, devido ao aumento da atividade metabólica, associada à atividade hormonal e à divisão e crescimento celular (Taiz \& Zeiger, 2004).

Levando em consideração a média dos valores de pontos de inflexão observados na cultura da soja (Figuras 5 a 10), 75 DAE (ponto de inflexão médio da soja para todos os macronutrientes estudados), uma planta de soja acumula teoricamente 23,9 g de massa seca, $564,4 \mathrm{mg}$ de $\mathrm{N}, 72,1 \mathrm{mg}$ de $\mathrm{P}, 490,8 \mathrm{mg}$ de $\mathrm{K}$, 487,0 mg de Ca, 156,6 mg de $\mathrm{Mg}$ e 36,0 mg de $\mathrm{S}$. Enquanto isso, para o mesmo período, uma planta de $S$. americanum acumula teoricamente $33,75 \mathrm{~g}$ de massa seca, $875,96 \mathrm{mg}$ de $\mathrm{N}, 88,46 \mathrm{mg}$ de $\mathrm{P}, 983,54 \mathrm{mg}$ de $\mathrm{K}, 647,60 \mathrm{mg}$ de Ca, 100,93 mg de Mg e 42,15 mg de S. Esses valores foram obtidos utilizando-se as equações apresentadas nas Figuras 5 a 10.

Após 63 DAE, há inversão na representatividade das folhas por caules para a espécie daninha e, após $49 \mathrm{DAE}$, existe uma inversão das folhas por caules e, posteriormente, por estruturas reprodutivas para a cultura da soja. A taxa de acúmulo diário dos macronutrientes atingiu seus maiores valores entre 69 e $87 \mathrm{DAE}$ para a soja e 105 e $119 \mathrm{DAE}$ para S. americanum.

Considerando a média dos valores de pontos de inflexão observados para a soja, temse que, aos $75 \mathrm{DAE}$, a planta cultivada acumula menos massa seca e, também, macronutrientes do que a planta daninha, no mesmo período.
Assim, S. americanum poderá trazer muito prejuízo para a cultura da soja em termos de competição por macronutrientes, além de ocasionar sérios problemas durante a colheita, ocasião na qual a planta daninha apresenta franco desenvolvimento, podendo, dessa maneira, criar problemas operacionais para a colheitadeira e provocar ardimento dos grãos, pois o material vegetal ainda se encontra em crescimento; por conseguinte, é úmido, além de verde. Poderá também ser prejudicial à soja no que diz respeito à contaminação dos grãos com sementes dessa espécie, prejudicando a qualidade do produto final, principalmente quando destinado à produção de sementes.

\section{LITERATURA CITADA}

BAKER, H. The evolution of weeds. Econ. Bot., v. 37, n. 2, p. 255-282, 1974.

BIANCO, S.; CARVALHO, L. B.; BIANCO, M. S. Growth and mineral nutrition of Solanum americanum. Planta Daninha, v. 28, n. 2, p. 293-299, 2010.

BLANCO, H. G.; FRATINI, M. P. Catálogo das espécies de mato infestantes de áreas cultivadas no Brasil - família do amendoim do campo (Leguminosae). Biológico, v. 19, n. 2, p. 33-68, 1978.

CARVALHO, L. B. et al. Estudo comparativo do acúmulo de massa seca e macronutrientes por plantas de milho var. BR 106 e Brachiaria plantaginea. Planta Daninha, v. 25, n. 2, p. 293-301. 2007. 
CHART, B. W. et al. Maple V: language reference manual. NewYork: Springer-Verlag, 1991. 411 p.

DUARTE, D.J. et al. Crescimento e nutrição mineral de Ipomoea nil. Planta Daninha, v. 26, p. 577-583, 2008. (Número Especial).

FAYAD, J. A. et al. Absorção de nutrientes pelo tomateiro cultivado sob condições de campo e de ambiente protegido. Hortic. Bras., v. 20, n. 1, p. 90-94, 2002.

HOAGLAND, D. R.; ARNON, D. J. The water culture method of growing plants without soil. Berkeley: University of California, 1950. $32 \mathrm{p}$.

HUETT, D. O.; DETTMAN, B. Effect of nitrogen on growth, fruit quality and nutrient uptake of tomatoes grown in sand culture. Austr. J. Exper. Agric., v. 28, n. 3, p. 391-399, 1988.

JORGENSEN, S. S. Metodologia utilizada para análises químicas de rotina: guia analítico. Piracicaba: CENA, 1977. 24 p.
NEPOMUCENO, M. et al. Períodos de interferência das plantas daninhas na cultura da soja nos sistemas de semeadura direta e convencional. Planta Daninha, v. 25, n. 1, p. 43-50, 2007.

PEREIRA, F. A. R.; VELINI, E. D. Sistemas de cultivo no cerrado e dinâmica de populações de plantas daninhas. Planta Daninha, v. 21, n. 3, p. 355-363, 2003.

PITELLI, R. A. Interferência de plantas daninhas em culturas agrícolas. Inf. Agropec., v. 11, n. 1, p. 16-27, 1985.

SARRUGE, J. R.; HAAG, H. P. Análises químicas em plantas. Piracicaba: ESALQ/USP, 1974. 56 p.

STATSOFT. Data analysis software system. Version 6.0. Disponível em: <http://www.statsoft.com>. Acesso em: 16 jul. 2007.

TAIZ, L.; ZEIGER, E. Plant physiology. Redwood: The Benjamin \& Cummigs Publishing Co., 2004. 559 p.

VITTI, G. C. Avaliação e interpretação do enxofre no solo e na planta. Jaboticabal: FUNEP, 1989. 37 p. 